\title{
The clinical effect of $\beta$-elemene-assisted radiochemotherapy in the treatment of esophageal cancer: a systematic review and meta-analysis
}

\author{
Chenxi Li ${ }^{1,2,3}$, Yiying Zeng ${ }^{1,2,3,4}$, Nana Zhang ${ }^{1,2,3}$, Bingtao Zhai ${ }^{5}$, Chao Zhang ${ }^{1,2,3}$, Yao Zhu ${ }^{1,2,3}$, \\ Zhaowu Zeng ${ }^{1,2,3}$, Tian Xie ${ }^{1,2,3}$
}

${ }^{1}$ Holistic Integrative Pharmacy Institutes, Hangzhou Normal University, Hangzhou 311121, China; ${ }^{2}$ Key Laboratory of Elemene Class Anticancer Chinese Medicine of Zhejiang Province, Hangzhou 311121, China; ${ }^{3}$ Engineering Laboratory of Development and Application of Traditional Chinese Medicine from Zhejiang Province, Hangzhou 311121, China; ${ }^{4}$ Institute of Chinese Materia Medica, Shanghai University of Traditional Chinese Medicine, Shanghai 201203, China; ${ }^{5}$ College of Pharmacy, Chengdu University of Traditional Chinese Medicine, Chengdu 611137, China Contributions: (I) Conception and design: C Li; (II) Administrative support: T Xie, Z Zeng; (III) Provision of study materials or patients: C Li; (IV) Collection and assembly of data: C Li, Y Zeng, N Zhang, B Zhai; (V) Data analysis and interpretation: C Li; (VI) Manuscript writing: All authors; (VII) Final approval of manuscript: All authors.

Correspondence to: Tian Xie; Zhaowu Zeng. Holistic Integrative Pharmacy Institutes, Hangzhou Normal University, 1378 Wenyixi road, Hangzhou 311121, China. Email: xbs@dljg.sina.net; artgreenking@126.com.

Background: The involvement of traditional Chinese medicine $\beta$-elemene in the treatment of esophageal cancer with radiochemotherapy could make a difference on clinical outcomes. This meta-analysis was conducted to analyze the safety and efficacy of helpful role with $\beta$-elemene in assisting the treatment of radiochemotherapy.

Methods: Literature retrieval was performed in Chinese Journal Full-text Database, Wanfang Database, China Biological Science Literature Database, VIP Knowledge Resource System, Web of Science, PubMed and assisted in other searches. Randomized controlled trials (RCTs) to evaluate effects of $\beta$-elemene-assisted radiochemotherapy for EC were identified. Data extracted from documents that meet the inclusion criteria we defined. Review Manager 5.3 (RevMan5.3) was used for data analysis.

Results: A total of 14 studies were included with 1,034 individuals. The results of Meta-analysis indicated that the esophageal cancer (EC) patients received $\beta$-elemene adjuvant therapy were superior to the control group in improving the response rate [odds radio $(\mathrm{OR})=0.14,95 \%$ confidence intervals (CIs): 0.09-0.19, $\mathrm{P}<0.00001]$ and the quality of life $(\mathrm{OR}=2.62,95 \% \mathrm{CI}: 1.52-4.53, \mathrm{P}=0.0005)$. Compared with the control group that only received chemoradiotherapy, the EC patients received $\beta$-elemene adjuvant therapy had obvious advantages in the indicators of 2-year survival rate $(\mathrm{OR}=1.78,95 \% \mathrm{CI}: 1.18-2.66, \mathrm{P}=0.006), 1$-year local control rate $(\mathrm{OR}=1.95,95 \% \mathrm{CI}: 1.17-3.27, \mathrm{P}=0.01)$ and 2 -year local control rate $(\mathrm{OR}=1.98,95 \% \mathrm{CI}$ : 1.23-3.17, $\mathrm{P}=0.005)$ respectively. More importantly, the EC patients received $\beta$-elemene adjuvant therapy yielded better outcomes compared to the control group about myelosuppression rate (OR $=0.73,95 \% \mathrm{CI}$ : 0.55-0.97, $\mathrm{P}=0.03)$.But in decreasing the incidence of alimentary canal reactions ( $\mathrm{OR}=0.87,95 \%$ CI: $0.64-$ $1.17, \mathrm{P}=0.34)$, radiation pneumonitis $(\mathrm{OR}=0.01,95 \% \mathrm{CI}:-0.07$ to $0.09, \mathrm{P}=0.81)$ and radiation esophagitis $(\mathrm{OR}=-0.01,95 \% \mathrm{CI}:-0.09$ to $0.07, \mathrm{P}=0.79)$, there was no remarkable statistical difference between two groups.

Conclusions: The $\beta$-elemene-assisted radiochemotherapy in treatment of EC to improve short term effect, 2-year survival rate, 1-year local control rate and 2-year local control rate. The treatment group has showed positive impact on improve the quality of life and reduce the myelosuppression rate.

Keywords: $\beta$-elemene; esophageal cancer (EC); meta-analysis; randomized trial; radiochemotherapy 
Submitted Sep 02, 2018. Accepted for publication Nov 28, 2018.

doi: 10.21037/tcr.2018.12.05

View this article at: http://dx.doi.org/10.21037/tcr.2018.12.05

\section{Introduction}

Esophageal cancer (EC), a highly invasive gastrointestinal cancer, develops in the inner layers of the mucosa (lining) of the esophagus. According to histological classification, there are two main types of EC, including esophageal squamous cell carcinoma (ESCC) and esophageal adenocarcinoma (EAC) adenocarcinoma (1). The incidence rate ranks seventh in malignant tumors (2). According to estimate, there were 456.000 new cases of EC globally (3), and China with the highest incidence (4). Worldwide, Asia, Southeast Africa, Northern France and South America are high distributive district of EC. EAC is the major EC type in developed countries of Europe and American, and ESCC are more than 95 percent of the EC patients in China (5). Exactly what causes EC is unclear, but several factors are linked to the disease, living conditions, dietary patterns, lifestyle, genetic factors and so on $(5,6)$. In Europe and American, tobacco and alcohol drinking were reported to be the primary causes/risk factors for EAC, contributing to more than $90 \%$ of case occurrences (7). The viewpoint of dietary habits and dietary patterns is broadly related to ESCC has been confirmed by growing scientific studies $(7,8)$. A population-based case-control study was intended to explore the association between temperature of food and the risk of ESCC, the results showed that high temperature of water and food intake increased the risk of ESCC by more than 2-fold (8). The outcome produced by another population-based case-control study emphasized the significance of good diets (rich in vegetables and fruits) for decreasing the risk of ESCC (9).

The patients that have been diagnosed as EC are mostly in advanced stage, owing to the early symptoms of patients with EC are inconspicuous. It is extremely difficult to remove the tumor completely by surgery for advanced EC patients, according to statistics, the 5 -year survival rate after surgery alone is 25 percent and less than 60 percent of EC patients that had been through the radical, which result in the EC patients with poor prognosis and less than ideal long-term survival rate (10-14). The meta-analysis reveals that none of esophagectomy plus chemoradiotherapy in locally advanced ESCC makes any difference on overall survival compared to chemoradiotherapy alone (15).
Therefore, comprehensive treat based on radiotherapy and chemotherapy is still the main treatment for most EC patients during clinical practice (16). But related research shows that preoperative chemoradiotherapy does not obviously improve progression-free or overall survival for EC patients compared with surgery alone (17). Another experimental result shows that the overall 5-year survival rate was beneficial to CRT (the EC patients with definitive chemoradiotherapy) compared to the EC patients with standard esophagectomy, but the difference did not reach statistical significance (surgery $29.4 \%$ and CRT $50 \%$, $\mathrm{P}=0.147)(18)$. It seems to be a choice that increasing the dose of radiotherapy and chemotherapy in order to get close to the desired therapeutic effect. However, there is currently no clinical standard for the dose of radiotherapy for EC patients, the actual dose of radiotherapy ranges from 50 to 70 Gy. The EC patients in Asian countries who received $\geq 60$ Gy radiation had a better prognosis as compared with $<60$ Gy. But two studies from western countries provided conflicting results for $\geq 60$ Gy and showed that the increase risk for adverse effects, so the advantage of $\geq 60$ Gy radiation in Western countries still remains controversial $(19,20)$.

Increased doses while increasing side effects, shortening lifespan or decreasing quality of life, as well become focus issues identically (21). How to further improve the therapeutic result of radiotherapy or chemotherapy without increasing toxicity of normal tissues is still a worldwide problem which has not been conquered yet. Study of radio sensitizer or chemosensitizer agent is becoming one of the hotpots in the field of clinical therapy (22). Traditional Chinese medicine as an adjuvant therapy cooperated with radiochemotherapy is considered as an effective treatments throughout the treatment cycle, because not only could which control the progress of cancer, but also can regulate immune function of patients and alleviate the adverse reactions caused by radiotherapy and chemotherapy $(23,24)$.

Elemene, a natural sesquiterpene extracted from the Traditional Chinese Medicine Curcuma Wenyujin, is the most contributing component of $\beta$-elemene (25). It is considered that $\beta$-elemene has advantages of broadspectrum to tumor cells and low toxicity level to normal cells over other traditional drugs (26). As a broad-spectrum antitumor agent assisted to regular cancer treatment, a 
mass of evidences provided by medical studies from home and abroad have demonstrated that $\beta$-elemene is beneficial to enhance the effect of anti-tumor and reduce side effects caused by radiotherapy and chemotherapy (27). Beyond that in some studies have pointed that $\beta$-elemene improves curative effect of radiosensitization in several cancer cells lines, including human renal cancer cells, human tongue squamous cancer cells and NSCLC cells and refreshes sensitivity of NSCLC cells to cisplatin via a mitochondriamediated intrinsic apoptosis pathway concerning Bcl-2 family proteins and IAPs (inhibitor of apoptosis proteins) (28-30).

Previous studies revealed that $\beta$-elemene exhibited its anti-cancer activities by targeting major signaling pathways (31) and related experiments have shown that radiation-induced cell death can be significantly increased by $\beta$-elemene pretreated gastric cancer cell line MKN45 compared to cells not treated with $\beta$-elemene. The destiny of the cancer cell receiving the radiotherapy are under the control of the signaling transduction (32) and the activation of ERK1/2 could twist the destiny by facilitating the damage repair process in cancer cells and providing protection from radiotherapy damage and improving cell survival (33). Pak1 is associated with a variety of biological functions and signaling pathways. Related studies have proved that it is over-expressed and/or over-activated in most cancers, including gastric cancer (34). Previous studies have demonstrated that Pak1 is located upstream of ERK1/2 signaling and can activate ERK1/2 in a kinasedependent or independent manner $(35,36)$. Targeting Pak1 signaling is a method of increasing the sensitivity of cancer cells to radiotherapy, the radiosensitivity of gastric cancer cells could be improved by restraining of Pak1 and its downstream ERK1/2 signaling in the treatment of $\beta$-elemene-assisted radiotherapy.

Nowadays, $\beta$-elemene with radiotherapy or chemotherapy is broadly adopted in the clinical treatment of EC in China. Based on previous research on the treatment of $\beta$-elemene in cancer, namely, the auxiliary role of $\beta$-elemene in tumor radiotherapy and chemotherapy. To further demonstrated the role of it in improving clinical efficacy, and increasing chemosensitization or radiosensitization of tumor cells. Hence, a meta-analysis performed with the purpose of providing reliable and latest evidence of effectiveness and safety of $\beta$-elemene assisted to radiotherapy or chemotherapy or radiochemotherapy for EC treatment.

To compare the effectiveness and safety of $\beta$-elemeneassisted radiochemotherapy with that of radiochemotherapy alone in EC patients, under the results of the response rate, KPS score improvement rate, survival rate, local control rate and myelosuppression rate.

\section{Methods}

\section{Identification of the related studies}

Published studies were retrieved from Embase, PubMed, VIP, Wanfang and China National Knowledge. A retrieval model was established using key words and medical subject headings ( $\beta$-elemene) including Esophagus cancer" "Radiotherapy" "Chemotherapy, EC, esophageal carcinoma. The search strategy was subsequently modified and fit for other databases. Study timespan covered period from January 1st, 1998 to May 15th, 2018. All randomized controlled trials (RCTs) were reviewed as the systematic literature review in Chinese and English.

\section{Inclusion/exclusion criteria}

We evaluated for eligibility, all peer-reviewed articles published between January, 1998 and May, 2018, which must meet the following inclusion criteria: to analyze the effect of $\beta$-elemene-assisted radiotherapy and chemotherapy on EC patients, case-control study, specific radiotherapy and chemotherapy regimens and relevant outcomes, RCTs with complete data to calculate odds ratios (ORs) and 95\% confidence intervals (CIs). Exclusion criteria: non-RCTs; duplication of previous publications; review and editorial; patients in the treatment group were treated with $\beta$-elemene alone or with other treatment options; study with no precise data counting on response rate. There was no restriction based on study design, the age of participants and their gender.

\section{Study cases and interventions}

All patients were certified by pathological histology or cytology as esophageal squamous cell carcinoma, no metastasis were found with CT scan and ultrasonic B, excluding patients with radiochemotherapy contraindications, liver and kidney dysfunction, and KPS scores less than 60 points. In this meta-analysis, the included randomized trials met the following requirements. The intervention treatment group was treated with $\beta$-elemene-assisted radiotherapy or chemotherapy or radiotherapy and chemotherapy and the control group was treated with only radiotherapy or 


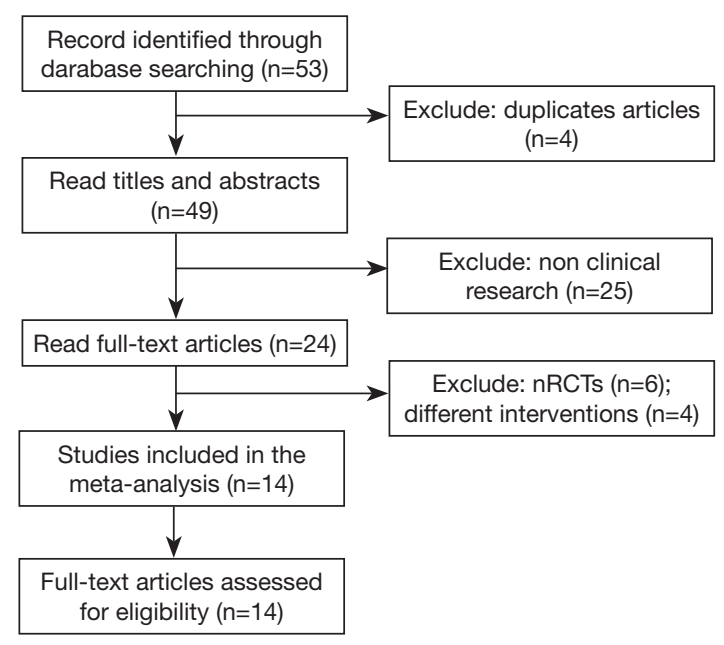

Figure 1 Search strategy.

chemotherapy or radiotherapy and chemotherapy.

\section{Data extraction}

First, the basic information extraction of the included studies, including the first author, year of publication, number of cases in the treatment intervention group and control group, demographic characteristics (age and gender), specific intervention plans, and corresponding results. Then the extraction of outcome data, including the response rates, Karnofsky Performance Status (KPS) score improvement rate, long-time survival rate, local control rate, myelosuppression rate etc.

\section{Quality assessment}

Quality assessment of each RCT was evaluated in terms of selective reporting, The evaluation included: (I) whether random sequences were generated; (II) whether random allocation concealment; (III) whether blinded to subjects and staff (IV) whether the evaluation of the result data is blinded; (V) the integrity of the result data; (VI) selective reporting of the study results (VII) other sources of bias. Using the Cochrane Correspondence Network RCT evaluation tool to evaluate each item according to low risk (+), unknown risk (?) high risk (-) (37). The Risk of bias graph and the risk of bias summary were generated with Review Manager (RevMan) [Computer program]. Version 5.3.

\section{Statistical analysis}

The estimated odds ratio (OR) with $95 \%$ confidence intervals (CIs) was used to summarize the response rates, KPS score improvement rate, long-time survival rate, local control rate, myelosuppression rate, radiation pneumonitis, and radiation esophagitis and incidence of alimentary canal reactions. Chi-square test was used in assessment the existence of statistical heterogeneity and $\mathrm{I}^{2}$ value indicates the degree of heterogeneity, $\mathrm{I}^{2}$ of $<40 \%$ indicates low heterogeneity. If outcomes with low heterogeneity, a fixed-effect model was used; otherwise random effects models were used. The $\mathrm{P}$ value threshold for statistical significance was set at 0.05 for effect sizes (38). Publication bias was tested using the funnel plot. All statistical analyses were performed using STATA (version 14.0; StataCorp LLC, Lakeway Drive, College Station, TX) and RevMan (version 5.3).

\section{Results}

Fifty-three studies were obtained by online and manual search. After removing duplicate studies and reading headlines and summaries, fourteen studies were matched with the inclusion criteria, we excluded 6 trials were nonRCTs, 4 trials adopted different intervention measures. In the end, 14 studies were identified that included a total of 1,034 esophagus cancer patients, and 522 patients with the treatment assisted by $\beta$-elemene-assisted were designated as the experimental group. The rest of 512 patients who only received conventional treatment were designated as the control group. According to the selection criteria, papers were extracted from the databases as shown in Figure 1. The main features of all 14 included studies in Table 1 and the characteristics of the included patients' condition in Table 2.

\section{Risk of bias}

The work in this part is done by the first author and the third author. Evaluate the risk of bias based on the quality of the included RCTs in Figure 2. There are 12RCTs involved randomization in the 14 RCTs included, and 5 RCTs description of stochastic method (random number table), none of the studies provided specific information on allocation concealment and blinding but all included 


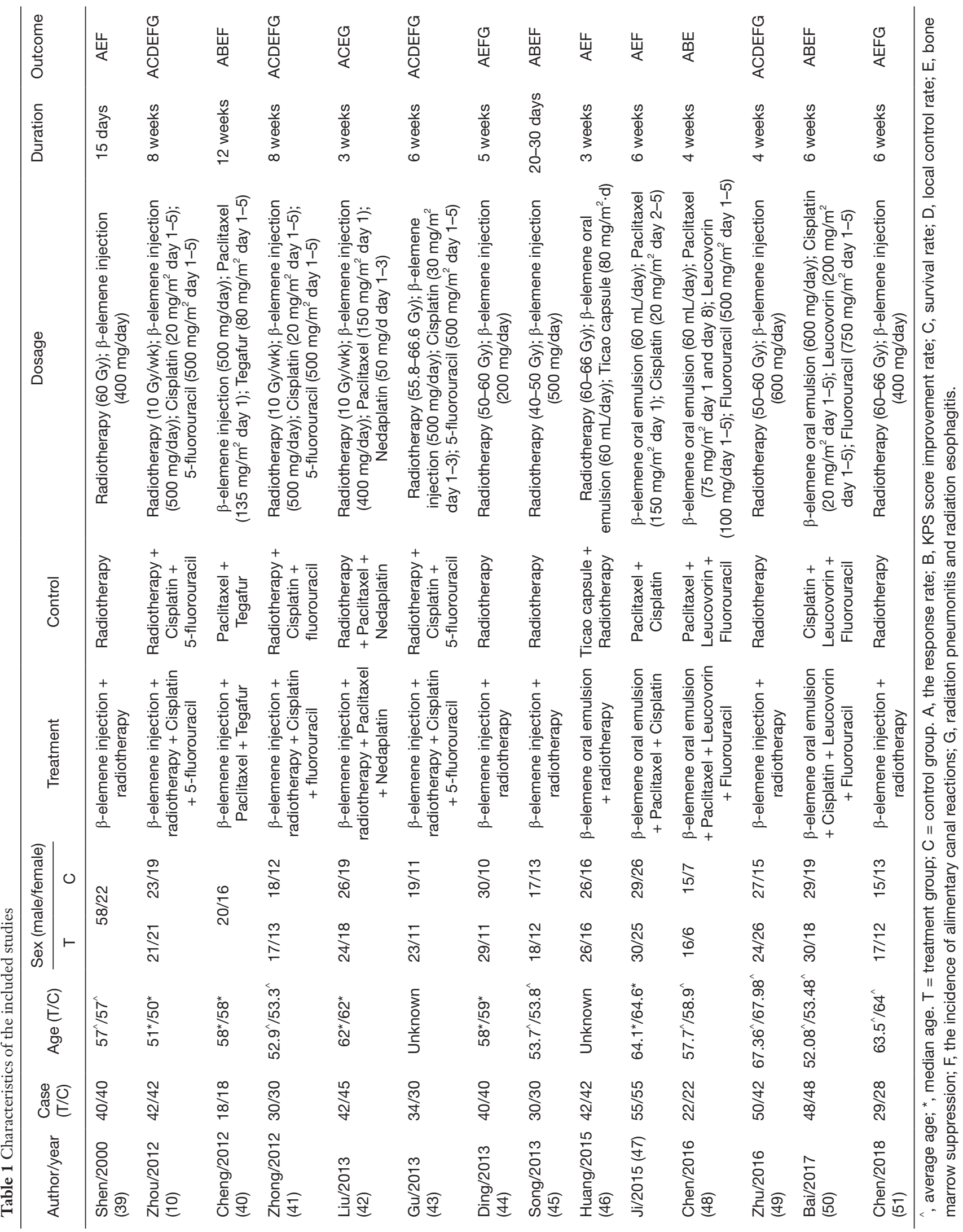


Table 2 Characteristics of the included patients' condition

\begin{tabular}{|c|c|c|c|c|c|c|c|c|}
\hline Author/year & \multicolumn{2}{|c|}{ Clinical stages (TNM) } & \multicolumn{2}{|c|}{ Pathologic types } & \multicolumn{2}{|c|}{ Lesion location } & \multicolumn{2}{|c|}{ Differentiation } \\
\hline Shen/2000 & \multicolumn{2}{|c|}{ Advanced stage } & \multicolumn{2}{|c|}{$78 / 2$} & \multicolumn{2}{|c|}{$\begin{array}{l}\text { Upper and medium: } 77 ; \\
\text { lower: } 3\end{array}$} & Unknown & Unknown \\
\hline Zhou/2012 & $\begin{array}{l}\text { Stage II: } 11 ; \\
\text { stage III: } 39\end{array}$ & $\begin{array}{l}\text { Stage II: } 11 \\
\text { stage III: } 31\end{array}$ & $42 / 8$ & $37 / 5$ & $\begin{array}{l}\text { Upper: 10; } \\
\text { medium: 28; } \\
\text { lower: } 12\end{array}$ & $\begin{array}{l}\text { Upper: 6; } \\
\text { medium: 28; } \\
\text { lower: } 8\end{array}$ & $\begin{array}{l}\text { Low: } 12 \text {; } \\
\text { middle: } 28 \text {; } \\
\text { high: } 10\end{array}$ & $\begin{array}{l}\text { Low: } 10 \text {; } \\
\text { middle: } 23 \text {; } \\
\text { high: } 9\end{array}$ \\
\hline Cheng/2012 & \multicolumn{2}{|c|}{ Advanced stage } & Unknown & Unknown & Unknown & Unknown & Unknown & Unknown \\
\hline Zhong/2012 & $\begin{array}{l}\text { Advance stage: } 10 ; \\
\text { other stage: } 20\end{array}$ & $\begin{array}{l}\text { Advance stage: } 12 ; \\
\text { other stage: } 18\end{array}$ & 19/d11 & $20 / 10$ & $\begin{array}{l}\text { Upper: 5; } \\
\text { medium: 19; } \\
\text { lower: } 6\end{array}$ & $\begin{array}{l}\text { Upper: 6; } \\
\text { medium: 18; } \\
\text { lower: } 6\end{array}$ & Unknown & Unknown \\
\hline Liu/2013 & $\begin{array}{l}\text { Stage I: } 8 \text {; stage } \\
\text { II: 19; stage III: 11; } \\
\text { stage IV: } 4\end{array}$ & $\begin{array}{l}\text { Stage I: } 6 \text {; stage } \\
\text { II: } 20 \text {; stage III: } 13 \text {; } \\
\text { stage IV: } 6\end{array}$ & $41 / 1$ & $43 / 2$ & $\begin{array}{l}\text { Upper: 6; } \\
\text { medium: 26; } \\
\text { lower: } 10\end{array}$ & $\begin{array}{l}\text { Upper: 5; } \\
\text { medium: 29; } \\
\text { lower: } 11\end{array}$ & $\begin{array}{l}\text { Low: } 14 \text {; } \\
\text { middle: } 17 \text {; } \\
\text { high: } 11\end{array}$ & $\begin{array}{l}\text { Low: } 12 \text {; } \\
\text { middle: } 15 \text {; } \\
\text { high: } 18\end{array}$ \\
\hline Ding/2013 & \multicolumn{2}{|c|}{ Advanced stage } & $40 / 0$ & $40 / 0$ & $\begin{array}{l}\text { Upper: 12; } \\
\text { medium: } 28\end{array}$ & $\begin{array}{l}\text { Upper: 11; } \\
\text { medium: } 29\end{array}$ & Unknown & Unknown \\
\hline Song/2013 & $\begin{array}{l}\text { Advance stage: } 11 ; \\
\text { other stage: } 19\end{array}$ & $\begin{array}{l}\text { Advance stage: } 12 ; \\
\text { other stage: } 18\end{array}$ & Unknown & Unknown & $\begin{array}{l}\text { Upper: 8; } \\
\text { medium: 16; } \\
\text { lower: } 6\end{array}$ & $\begin{array}{l}\text { Upper: } 7 ; \\
\text { medium: 16; } \\
\text { lower: } 7\end{array}$ & Unknown & Unknown \\
\hline Huang/2015 & Unknown & Unknown & $42 / 0$ & $42 / 0$ & $\begin{array}{l}\text { Upper: } 7 ; \\
\text { medium: 20; } \\
\text { lower: } 15\end{array}$ & $\begin{array}{l}\text { Upper: 9; } \\
\text { medium: 18; } \\
\text { lower: } 15\end{array}$ & Unknown & Unknown \\
\hline Zhu/2016 & $\begin{array}{l}\text { Stage III: } 11 \\
\text { stage IV: } 39\end{array}$ & $\begin{array}{l}\text { Stage III: } 11 \\
\text { stage IV: } 31\end{array}$ & $42 / 8$ & $37 / 5$ & $\begin{array}{l}\text { Upper: 10; } \\
\text { medium: } 28 ; \\
\text { lower: } 12\end{array}$ & $\begin{array}{l}\text { Upper: 6; } \\
\text { medium: 28; } \\
\text { lower: } 8\end{array}$ & $\begin{array}{l}\text { Low: } 12 \text {; } \\
\text { middle: } 28 \text {; } \\
\text { high: } 10\end{array}$ & $\begin{array}{l}\text { Low: } 10 \\
\text { middle: } 23 \text {; } \\
\text { high: } 9\end{array}$ \\
\hline Bai/2017 & \multicolumn{2}{|c|}{ Advanced stage } & $34 / 14$ & $35 / 13$ & Unknown & Unknown & Unknown & Unknown \\
\hline Chen/2018 & $\begin{array}{l}\text { Stage III: } 23 ; \\
\text { stage IV: } 6\end{array}$ & $\begin{array}{l}\text { Stage III: } 23 \\
\text { stage IV: } 5\end{array}$ & $29 / 0$ & $28 / 0$ & $\begin{array}{l}\text { Upper: 8; } \\
\text { medium: 15; } \\
\text { lower: } 6\end{array}$ & $\begin{array}{l}\text { Upper: 6; } \\
\text { medium: 14; } \\
\text { lower: } 8\end{array}$ & Unknown & Unknown \\
\hline
\end{tabular}

trials have a lower risk of bias towards incomplete data. We judged RCTs to be at unclear risk of other bias and selective bias due to insufficient relevant information provided. The author's summary of the risk assessment of bias is shown in Figure 3.

\section{Meta-analysis results}

\section{The response rate}

Of the 14 studies included, all RCTs encompassing 1,034 incident cases of EC (there were 522 patients in the 


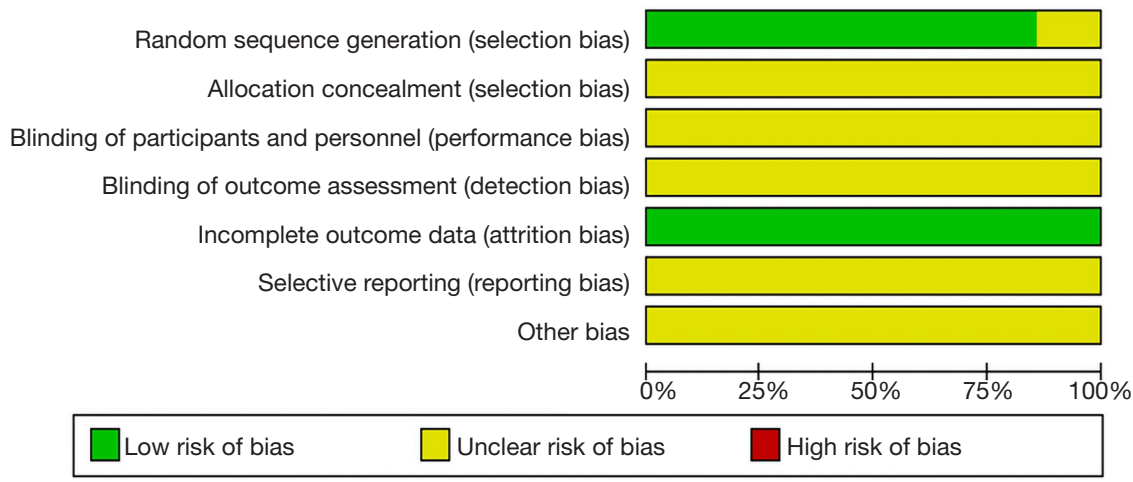

Figure 2 Risk of bias of the included studies.

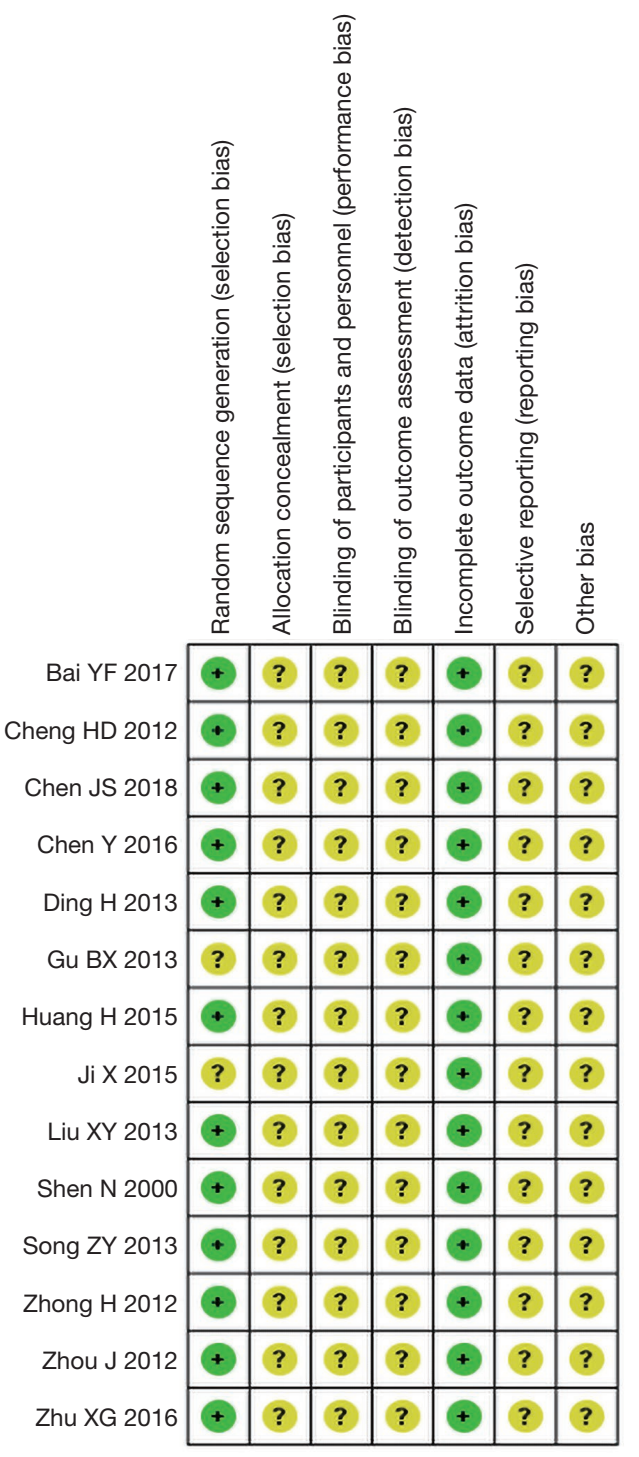

Figure 3 Authors' judgment on the risk of bias. experimental group treated with $\beta$-elemene and 512 cases of control group), evaluated the impact of $\beta$-elemene-assisted radiotherapy and chemotherapy on the response rate in EC patients. Overall, compared to not using $\beta$-elemene, the applications of $\beta$-elemene can increase the response rate of patients with $\mathrm{EC}(\mathrm{OR}=0.14,95 \%$ CI: 0.09-0.19, $\mathrm{P}<0.00001)$, with no significant heterogeneity $\left(\chi^{2}=12.58\right.$, $\mathrm{P}=0.48, \mathrm{I}^{2}=0 \%$ ) (Figure 4).

\section{KPS score improvement rate}

Only four RCTs encompassing 236 incident cases of esophagus cancer (there were 118 patients in the experimental group treated with $\beta$-elemene; 118 cases of control group) evaluated the effect of $\beta$-elemene-assisted radiotherapy and chemotherapy on improvement of quality of life. There is a discrepancy between the experiment group and the control group in improving the quality of life, KPS score improvement rate of the patients with esophagus cancer expose to $\beta$-elemene-assisted radiotherapy and Chemotherapy was higher than the patients with conventional treatment $(\mathrm{OR}=2.62,95 \%$ CI: $1.52-4.53$, $\mathrm{P}=0.0005)$, without significant heterogeneity $\left(\chi^{2}=1.04\right.$, $\mathrm{P}=0.79, \mathrm{I}^{2}=0 \%$ ) (Figure 5).

\section{Survival rate}

Survival was analyzed based on long-term survival rate, which was reported in five RCTs with a total of 446 patients (198 patients in the experimental group treated with $\beta$-elemene, while 189 cases of control group). The 2-year long-term survival rate were analyzed, and no significant heterogeneity was observed in two analysis $\left(\chi^{2}=2.12\right.$, $\left.\mathrm{P}=0.71, \mathrm{I}^{2}=0 \%\right)$. There was significant difference between 


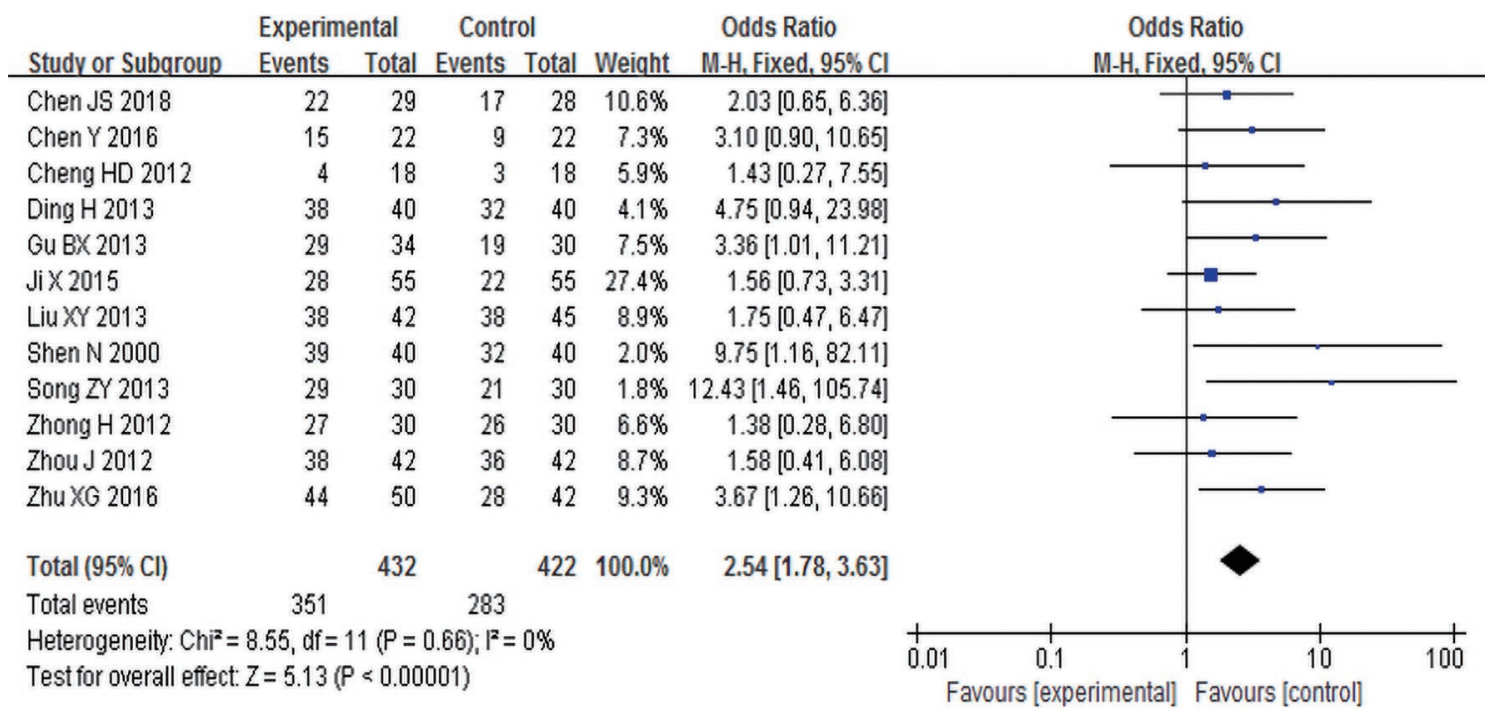

Figure 4 The forest plot of the response rate.

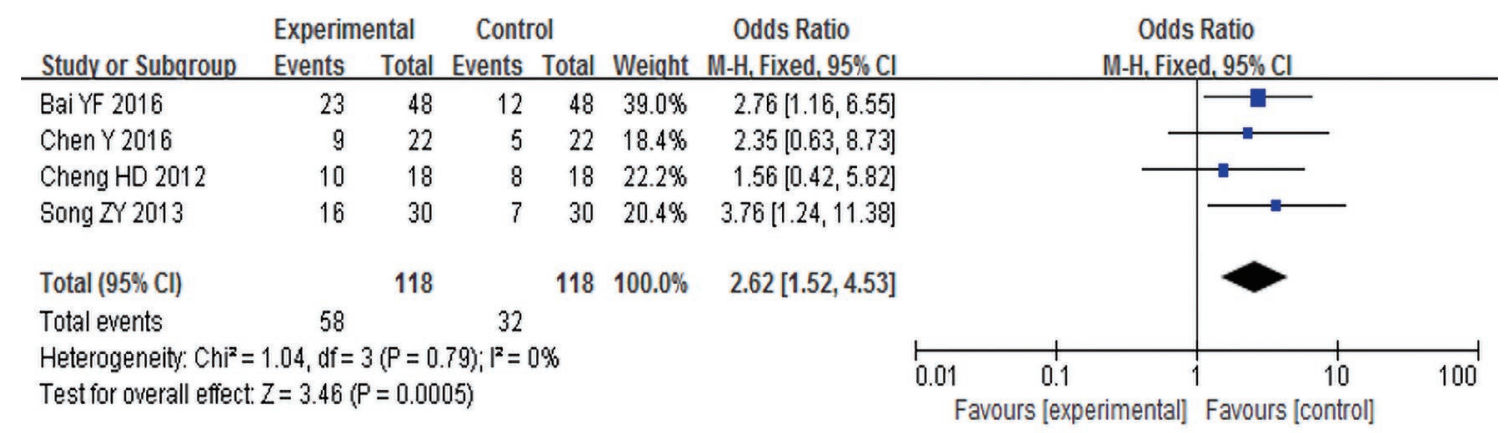

Figure 5 The forest plot of KPS score improvement rate.

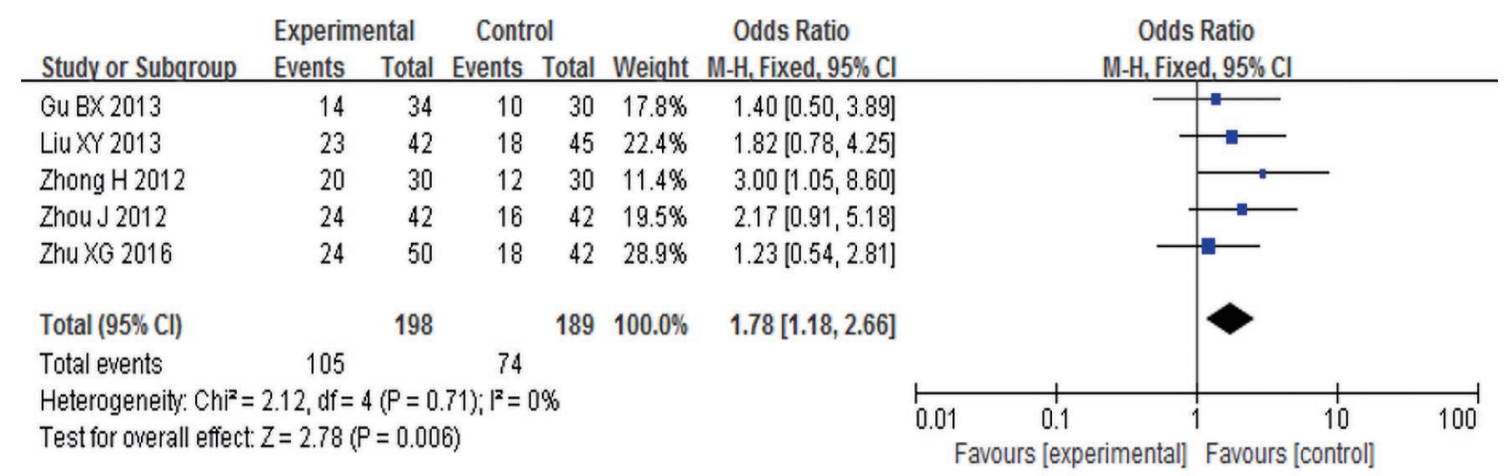

Figure 6 The forest plot of KPS The 2-year long-term survival rate.

the two groups concerning survival rate $(\mathrm{OR}=1.78,95 \%$ CI: 1.18-2.66, $\mathrm{P}=0.006), \beta$-elemene-assisted radiotherapy and Chemotherapy was associated with a significant prolongation of survival (Figure 6).

\section{Local control rate}

Four RCTs provided data for Local control rate with a total of 300 patients (there were 156 patients in the experimental group treated with $\beta$-elemene, while 144 cases of control 


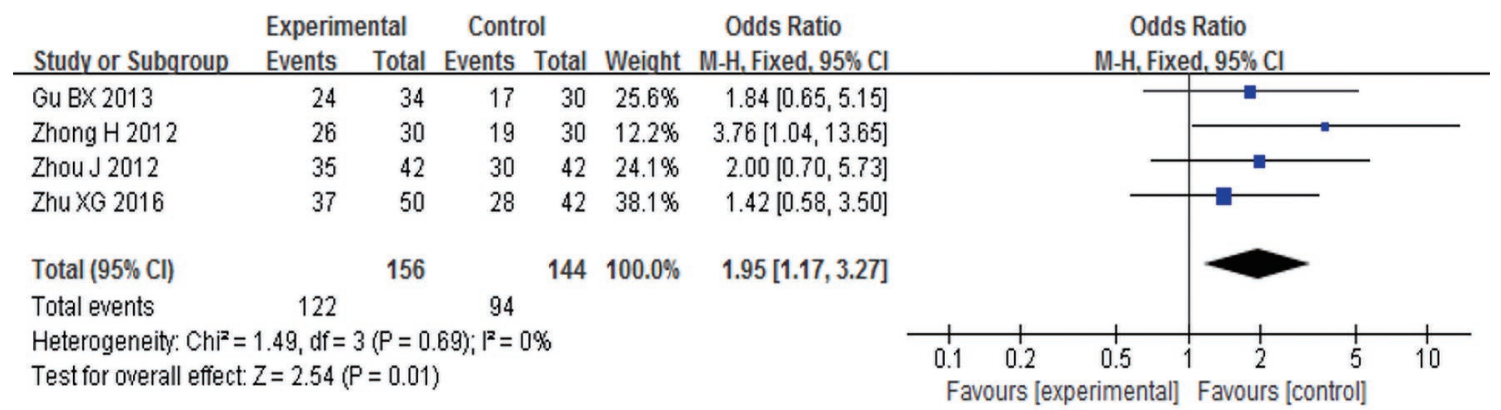

Figure 7 The forest plot of 1-year local control rate.

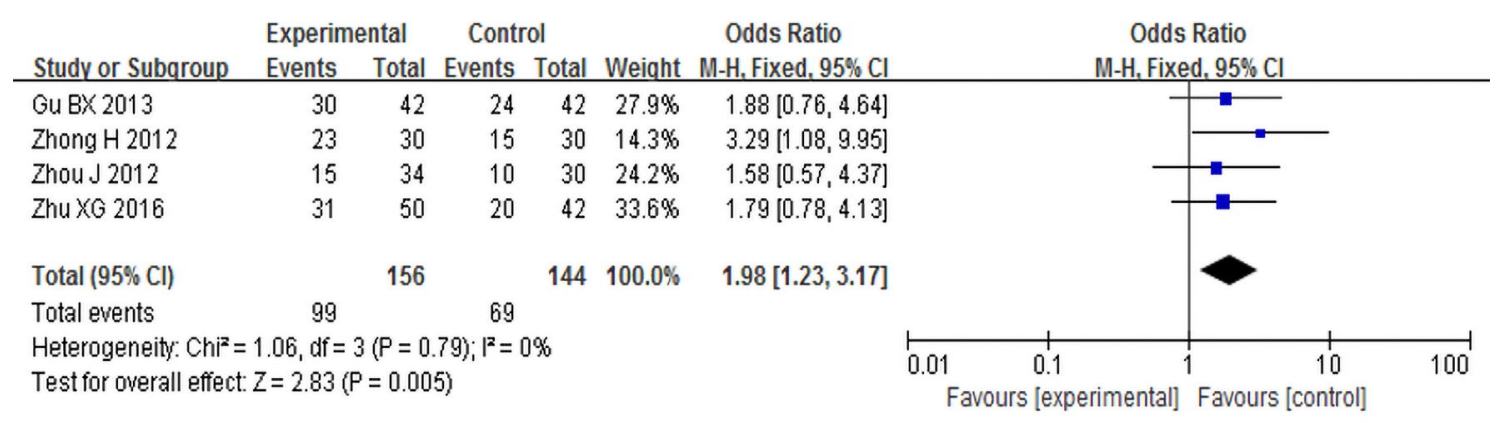

Figure 8 The forest plot of 2-year local control rate.

group), and included 1-year local control rate $(\mathrm{OR}=1.95$, 95\% CI: $1.17-3.27, \mathrm{P}=0.01$ ) and 2-year local control rate $(\mathrm{OR}=1.98,95 \% \mathrm{CI}: 1.23-3.17, \mathrm{P}=0.005)$, and no heterogeneity was found in two in two analysis $\left(\chi^{2}=1.49\right.$, $\left.\mathrm{P}=0.69, \mathrm{I}^{2}=0 \%\right),\left(\chi^{2}=1.06, \mathrm{P}=0.79, \mathrm{I}^{2}=0 \%\right)$. The patients with esophagus cancer that received $\beta$-elemene had a more apparent local control rate compared with the control group with a significantly statistical difference (Figures 7,8).

\section{Adverse reactions}

Fourteen studies including reported AEs with different scope, the meta-analysis suggested that $\beta$-elemene-assisted chemoradiotherapy for esophageal could help decrease the incidence of myelosuppression, a common adverse reaction $(\mathrm{OR}=0.73$, 95\% CI: 0.55-0.97, $\mathrm{P}=0.03$ ) (Figure 9). But there is no obvious distinction for treatment group or for control group in other adverse reaction. The incidence of alimentary canal reactions $(\mathrm{OR}=0.87,95 \% \mathrm{CI}: 0.64-1.17$, $\mathrm{P}=0.34)$ (Figure 10), radiation pneumonitis $(\mathrm{OR}=0.01$, 95\% CI: -0.07 to $0.09, \mathrm{P}=0.81$ ) (Figure 11 ) and radiation esophagitis ( $\mathrm{OR}=-0.01,95 \% \mathrm{CI}:-0.09$ to $0.07, \mathrm{P}=0.79$ ) (Figure 12). Alimentary canal reactions and esophagitis and radiation gastritis in patients treated with $\beta$-elemene supplementation have not been alleviated compared with radiotherapy and chemotherapy alone. Most of the AEs returned to normalizes without additional treatment by reducing or stopping the dosage of intervention. However, the correlation between the AEs and the interventions were not further discussed in any study. No severe AEs were reported. The forest plot of the incidence of the response rate is given in Figure 13.

\section{Discussion}

The patients with EC had poor prognosis largely due to unapparent symptom at the early stage and tumor infiltration and metastasis, which also makes it hard to completely remove the tumor by surgery (12). Therefore, comprehensive treatment based on radiotherapy and chemotherapy is still the main treatment for most patients with advanced EC during clinical practice (16). The actual effect couldn't develop towards positive trend obviously by increasing radiation does simply, the risk of side effects such as radiation esophagitis and pneumonia could be increase conversely. The search for an effective radiosensitizer is an important and urgent issue for the treatment of EC (32). Traditional Chinese medicines have been concerned about as the radiosensitizers 


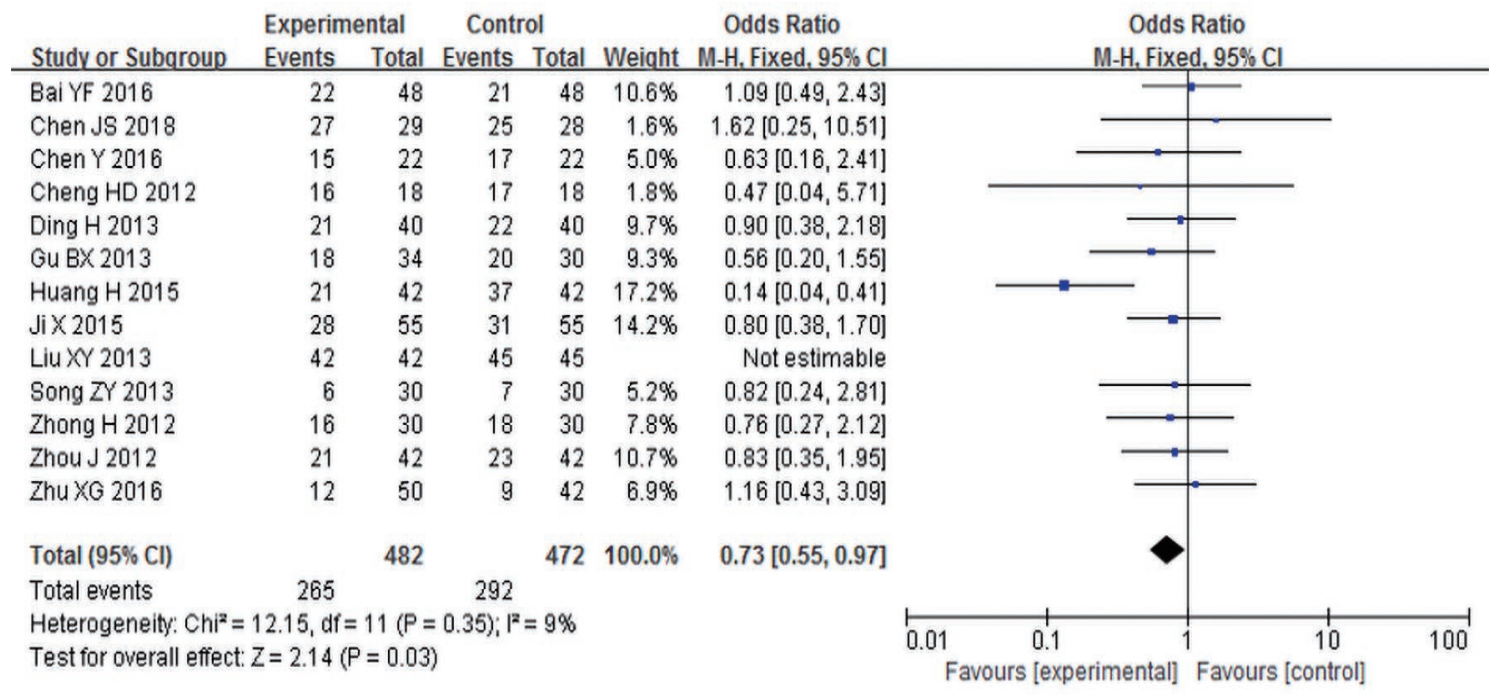

Figure 9 The forest plot of the incidence of myelosuppression.

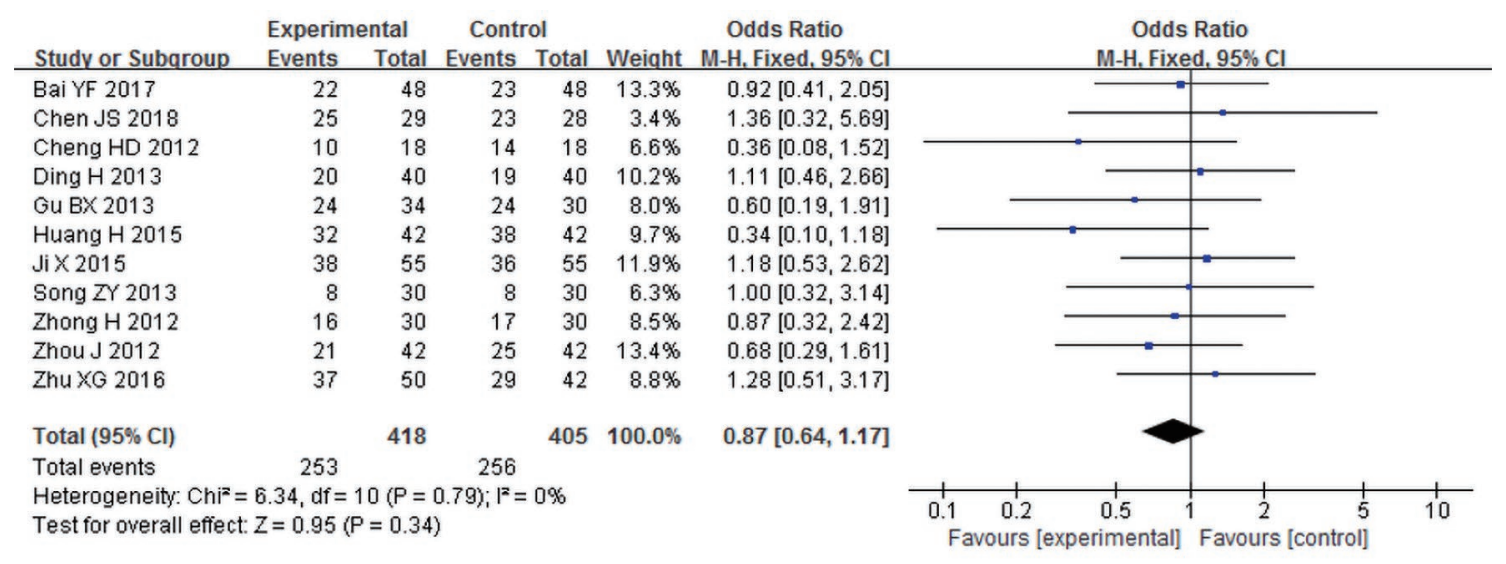

Figure 10 The forest plot of the incidence of alimentary canal reactions.

\begin{tabular}{|c|c|c|c|c|c|c|}
\hline \multirow[b]{2}{*}{ Study or Subqroup } & \multicolumn{2}{|c|}{ Experimental } & \multicolumn{2}{|c|}{ Control } & \multicolumn{2}{|r|}{ Odds Ratio } \\
\hline & Events & Total & Events & Total & Weight & M-H, Fixed, $95 \% \mathrm{C}$ \\
\hline Chen JS 2018 & 23 & 29 & 21 & 28 & $11.2 \%$ & $1.28[0.37,4.42]$ \\
\hline Ding $\mathrm{H} 2013$ & 9 & 40 & 8 & 40 & $15.7 \%$ & $1.16[0.40,3.40]$ \\
\hline Gu B× 2013 & 21 & 34 & 20 & 30 & $20.6 \%$ & $0.81[0.29,2.26]$ \\
\hline Zhong H 2012 & 19 & 30 & 17 & 30 & $15.8 \%$ & $1.32[0.47,3.72]$ \\
\hline Zhou J 2012 & 27 & 42 & 25 & 42 & $22.6 \%$ & $1.22[0.51,2.96]$ \\
\hline Zhu XG 2016 & 7 & 50 & 6 & 42 & $14.2 \%$ & $0.98[0.30,3.17]$ \\
\hline Total $(95 \% \mathrm{Cl})$ & & 225 & & 212 & $100.0 \%$ & $1.11[0.73,1.71]$ \\
\hline Total events & 106 & & 97 & & & \\
\hline \multicolumn{7}{|c|}{ Heterogeneity: $\mathrm{Chi}^{2}=0.62, \mathrm{df}=\left.5(\mathrm{P}=0.99)_{1}\right|^{2}=0 \%$} \\
\hline Test for overall effec & $7=0.50$ & $=0.62$ & & & & \\
\hline
\end{tabular}

Figure 11 The forest plot of the radiation esophagitis. 


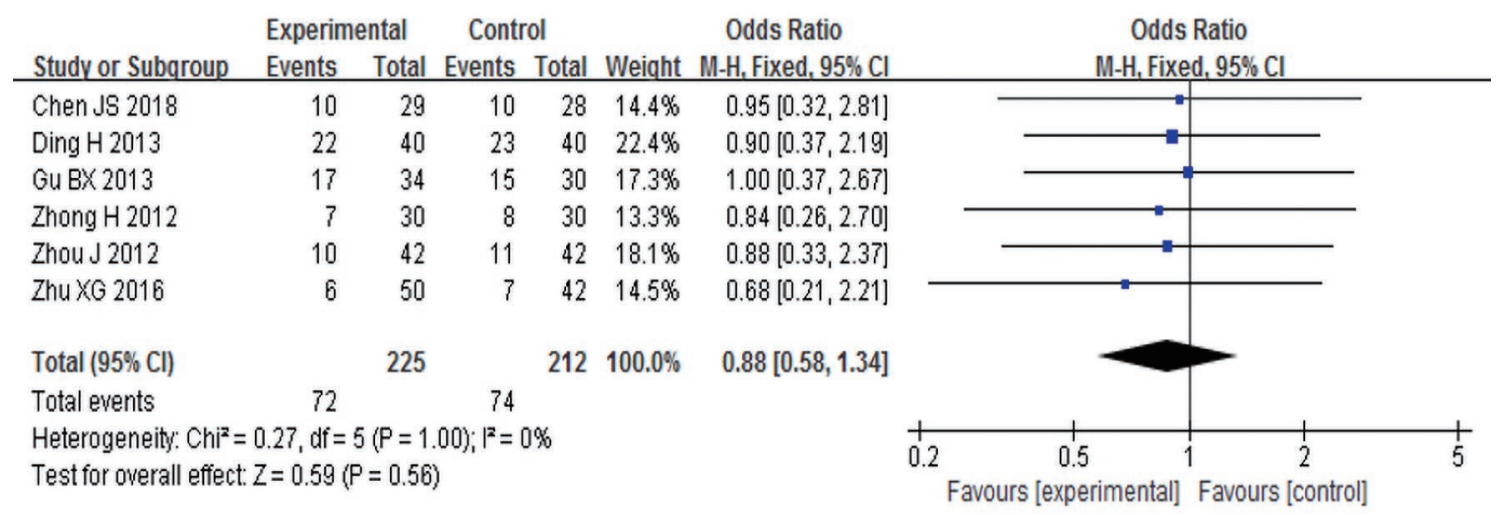

Figure 12 The forest plot of the radiation gastritis.

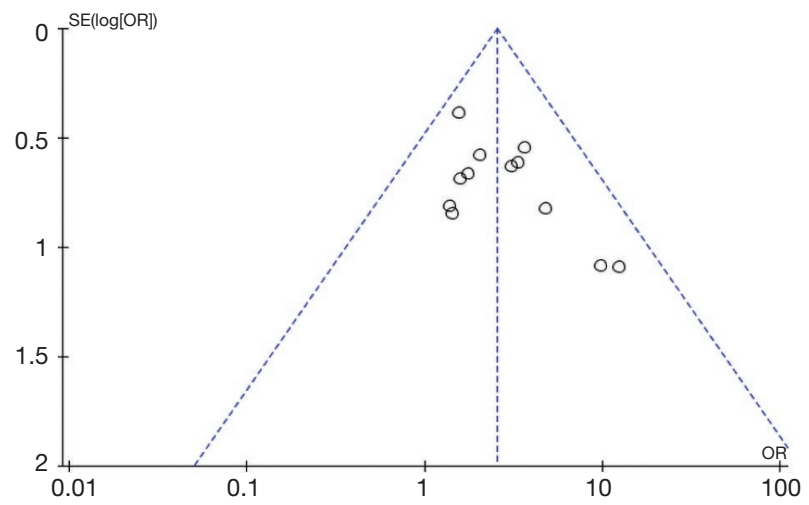

Figure 13 The funnel plot of the publication bias.

in treatment in recent years, with multiple targets, multiple effects, and fewer toxic and side effects (52).

$\beta$-elemene is a drug first extracted from the herbs in China such as Curcuma Wenyujin, that activates blood circulation in recent years. Several systematic reviews and meta-analyses regarding the efficacy and safety of $\beta$-elemene assisted chemoradiotherapy in lung cancer, gastric cancer, liver cancer, malignant brain tumors and other malignancies have been published (53).

Fourteen eligible RCTs with 1,034 patients were identified to obtain summary statistics in the present metaanalysis. The pooled results showed that $\beta$-elemene assisted chemoradiotherapy was available to significantly increase the response rate, KPS score improvement rate, local control rate and survival rate in patients with EC (54), which may be attributed to the effectiveness of $\beta$-elemene in inducing apoptosis of tumor cells, enhancing the radiotherapy sensitivity of tumor cells and reversing drug resistance, and more importantly $\beta$-elemene were found to suppressed the proliferation of esophageal carcinoma esophageal carcinoma ECA-109 cells by regulating the inhibition of human telomerase reverse transcriptase (hTERT) expression with a long noncoding RNA (lncRNA) recently (55), and also induced apoptosis of EC cell in the present experiments, the underlying mechanism of apoptosis would be related to the activation of caspase- 3 by $\beta$-elemene, most notably, the apoptosis regulated by caspase- 3 without reversibility. $\beta$-elemene were also found to marginally inhibit EC cell proliferation and induce apoptosis in, and activation of caspase-3 may be its underlying mechanism of apoptosis, most notably, the apoptosis regulated by caspase- 3 without reversibility $(56,57)$. The effectiveness of $\beta$-elemene in clinical cancer treatment has been proven, with clinical safety and non-toxic to normal cells (58). This may be the major reason that $\beta$-elemene-assisted chemoradiotherapy improves the response rate survival rate and local control rate of EC patients, and another possible reason is that $\beta$-elemene is a potential radiosensitizer.

Ten of the fourteen studies included involved radiotherapy treatment, the fact of the local recurrence and distant metastasis caused by the resistance effect in radiotherapy treatment, which makes it contribute a limited amount of effect in improving clinical efficacy, although radiation therapy is one of the main treatments for the EC patients currently (59). Due to myelosuppression and other toxicities caused by radiosensitizers, the role of it in clinical treatment remains not very reliable $(60,61)$. The metastasis and infiltration of tumor cells are largely related to the reduction of the immunogenicity of tumor cells, which capacitates the tumor cell to escape from immunological 
surveillance (62), it is known that heat shock proteins (HSPs) are related to the intracellular polypeptide antigen presentation and can present antigen within the tumor cells to the cell membrane so that the tumor cells can develop specific immunogenicity and trigger the body's specific antitumor immune $(63,64)$. The above mechanism involves the radiosensitizing properties of $\beta$-elemene, which may explain the reasons for the increase of e-mailed chemotherapy for EC patients to improve their effectiveness in the near future. In addition, the characteristics of $\beta$-elemene's reversal of drug resistance also play an important role in the treatment of adjuvant radiochemotherapy.

Seven of the 14 studies included involved chemotherapy treatment, and five of them were treated with cisplatin, the relevant study was conducted to prove that the chemosensitizing effects of $\beta$-elemene for increasing the cytotoxicity of cisplatin in gingival squamous cell carcinoma was achieved by decreasing the expressions of p-STAT3, p-JAK2, and Bcl-2, and increasing the expressions of Bax and caspase- 3 significantly (65). The study demonstrated that $\beta$-elemene enhancement of cisplatin-induced apoptosis via mitochondrial activation of the caspase-mediated apoptotic stated that chemosensitizing effect of $\beta$-elemene on cisplatin anti-tumour efficacy in androgen-independent prostate cancer (66). The experiments indicated that enhanced DNA repair capacity conduce to the build-up of cisplatin resistance in human cancers, the development of the cisplatin-resistance phenotype thanks to the increasing nucleotide excision repair (NER) of cisplatin-caused DNA damage (67), and ERCC-1 as DNA repair protein plays a major role in the NER process (68). The research showed that restoration of the sensibility in resistant human ovarian cancer cells for cisplatin was achieved by $\beta$-elemene via inhibiting cisplatin-induced ERCC-1 protein expression, that is to say, $\beta$-elemene could recover sensibility in resistant human ovarian cancer cells for cisplatin by interfering the process of repair of cisplatin-induced DNA damage (69). That said, $\beta$-elemene could reverse tumor resistance through various aspects-a window into $\beta$-elemene may be a kind of efficient reversal agent for clinic, which can provide evidence for improving the effect for EC patients receiving the treatment of $\beta$-elemene-assisted radiochemotherapy.

ATM kinase, a member of the phosphatidylinositol 3-kinase (PI3K)-like kinase family, activates more than 700 proteins involved in cell cycle checkpoints, DNA repair and modulation of chromatin structure, which are the key factors for efficient double-stand breaks (DSB) repair (70) and DSB is involved in regulating the response of tumor cells to radiotherapy and chemotherapy (71). The studies found that $\beta$-elemene significantly suppressed the repair of DNA damage of glioblastoma multiforme (GBM) cells combined with radiation or temozolomide (TMZ) via interfering with the ATM signaling pathways, enhanced both radiosensitivity and chemosensitivity of GBM through the inhibition of the ATM signaling pathway (72).

\section{Limitations}

This is a review of 14 studies proceeded over 20 years period. Some of the small sample studies themselves have an impact on the results, including the interference of other restrictions, Just as Insufficient reporting of randomization methods used in trials or poor methodological quality of RCTs. Corresponding allocation concealment is also not clear, the cannot tell accurately whether for selective reporting bias Due to the limited amount of information provided by all included studies (73). In addition, there is on deviation from the baseline between two groups, but the baselines were inconsistent between different studies. For example, the irradiation dose of radiation therapy, the chemotherapy protocol, and the course of treatment of each study are slightly different. Thence, Based on the above reasons, it is difficult to be absolutely objective and comprehensive to evaluate the effectiveness and safety of $\beta$-elemene-assisted radiochemotherapy in the treatment of EC. According to probable source of heterogeneity, we expect relevant researchers can well-designed on random experiments and strictly observed the Cochrane Handbook or CONSOR, and as far as possible to standard the treatment program (53).

\section{Conclusions}

Compared with radiotherapy and chemotherapy alone, $\beta$-elemene assisted EC radiotherapy can effectively improve the treatment effect, prolong survival time, improve quality of life, but also can reduce the adverse reactions caused by radiotherapy and chemotherapy to a certain extent. This may be because $\beta$-elemene has the characteristics of increasing radiosensitivity and reversing drug resistance. Although there is no large amount of experimental results to support the conclusion that $\beta$-elemene can reverse the drug resistance of EC cells, the study of other $\beta$-elemene reversal mechanism can bring new insights to EC related research and provides more evidence for the effect of treatment. Further comprehensive research requires a high-quality randomized 
clinical trial method to produce conclusive results.

\section{Acknowledgments}

Funding: This work was supported by Holistic Integrative Pharmacy Institutes, Hangzhou Normal University; Key Laboratory of Elemene Class Anti-cancer Chinese Medicine of Zhejiang Province; Engineering Laboratory of Development and Application of Traditional Chinese Medicine from Zhejiang Province; Key Projects of National Science Foundation of China (81730108); Key Project of Zhejiang project Ministry of Science and Technology (2015C03055); Key Project of Hangzhou Ministry of Science and Technology (20162013A07, 20142013A63).

\section{Footnote}

Conflicts of Interest: All authors have completed the ICMJE uniform disclosure form (available at http://dx.doi. org/10.21037/tcr.2018.12.05). The authors have no conflicts of interest to declare.

Ethical Statement: The authors are accountable for all aspects of the work in ensuring that questions related to the accuracy or integrity of any part of the work are appropriately investigated and resolved.

Open Access Statement: This is an Open Access article distributed in accordance with the Creative Commons Attribution-NonCommercial-NoDerivs 4.0 International License (CC BY-NC-ND 4.0), which permits the noncommercial replication and distribution of the article with the strict proviso that no changes or edits are made and the original work is properly cited (including links to both the formal publication through the relevant DOI and the license). See: https://creativecommons.org/licenses/by-nc-nd/4.0/.

\section{References}

1. Short MW, Burgers KG, Fry VT. Esophageal Cancer. Am Fam Physician 2017;95:22-8.

2. Siegel R, Naishadham D, Jemal A. Cancer statistics 2013. CA Cancer J Clin 2013;63:11-30.

3. Ferlay J, Soerjomataram I, Dikshit R, et al. Cancer incidence and mortality worldwide: sources, methods and major patterns in GLOBOCAN 2012. Int J Cancer 2015;136:E359-E386.

4. Jemal A, Bray F, Center MM, et al. Global cancer statistics. CA Cancer J Clin 2011;61:69-90.
5. Guideline for the diagnosis and treatment of esophageal cancer in Anhui Province (2016 version). Anhui Medicine 2018:127-42.

6. Wenbin H, Ting Z, Qin W, et al. Impact of esophageal cancer deaths on life expectancy and potential years of life lost from 1981 to 2015 in Kunshan, Jiangsu Province, China. China Oncology 2018;28:263-9.

7. Parkin D M, Bray F, Ferlay J, et al. Global cancer statistics 2002. CA Cancer J Clin 2005;55:74-108.

8. Tai WP, Nie GJ, Chen MJ, et al. Hot food and beverage consumption and the risk of esophageal squamous cell carcinoma: A case-control study in a northwest area in China. Medicine (Baltimore) 2017;96:e9325.

9. Liu X, Wang X, Lin S, et al. Dietary patterns and the risk of esophageal squamous cell carcinoma: A population-based casecontrol study in a rural population. Clin Nutr 2017;36:260-6.

10. Zhou J. Clinical research of concurrent chemoradiotherapy combined with $\beta$-Elemene Injection in the treatment of esophageal cancer. China Medical Herald 2012;9:69-70.

11. McNamara MJ, Adelstein DJ. Current developments in the management of locally advanced esophageal cancer. Curr Oncol Rep 2012;14:342-9.

12. Jiang L, Zhao X, Meng X, et al. Involved field irradiation for the treatment of EC: Is it better than elective nodal irradiation? Cancer Lett 2015;357:69-74.

13. Enzinger PC, Mayer RJ. Esophageal cancer. N Engl J Med 2003;349:2241-52.

14. Tytgat GN, Bartelink H, Bernards R, et al. Cancer of the esophagus and gastric cardia: recent advances. Dis Esophagus 2004;17:10-26.

15. Vellayappan BA, Soon YY, Ku GY, et al. Chemoradiotherapy versus chemoradiotherapy plus surgery for esophageal cancer. The Cochrane Library. John Wiley \& Sons, Ltd, 2013.

16. Suntharalingam M, Moughan J, Coia LR, et al. The national practice for patients receiving radiation therapy for carcinoma of the esophagus: Results of the 1996-1999 Patterns of Care Study. Int J Radiat Oncol Biol Phys 2003;56:981-7.

17. Burmeister BH, Smithers BM, Gebski V, et al. Surgery alone versus chemoradiotherapy followed by surgery for resectable cancer of the oesophagus: a randomised controlled phase III trial. Lancet Oncol 2005;6:659-68.

18. Teoh AY, Chiu PW, Yeung WK, et al. Long-term survival outcomes after definitive chemoradiation versus surgery in patients with resectable squamous carcinoma of the esophagus: results from a randomized controlled trial. Ann Oncol 2013;24:165-71.

19. Chen Y, Zhu HP, Wang T, et al. What is the optimal 
radiation dose for non-operable esophageal cancer? Dissecting the evidence in a meta-analysis. Oncotarget 2017;8:89095-107.

20. Song T, Liang X, Fang M, et al. High-dose versus conventional-dose irradiation in cisplatin-based definitive concurrent chemoradiotherapy for esophageal cancer: a systematic review and pooled analysis. Expert Rev Anticancer Ther 2015;15:1157-69.

21. Chen $\mathrm{W}$, Zheng R, Baade PD, et al. Cancer statistics in China 2015. CA Cancer J Clin 2016;66:115-32.

22. Jiang M, Qian X. Research progress of radiotherapy sensitization agents in the treatment for malignant tumor. Journal of Modern Oncology 2014;22:226-8.

23. Sagar SM, Wong RK. Chinese medicine and biomodulation in cancer patients--Part one. Curr Oncol 2008;15:42-8.

24. Qi F, Zhao L, Zhou A, et al. The advantages of using traditional Chinese medicine as an adjunctive therapy in the whole course of cancer treatment instead of only terminal stage of cancer. Biosci Trends 2015;9:16-34.

25. Wang G, Li X, Huang F, et al. Antitumor effect of $\beta$-elemene in non-small-cell lung cancer cells is mediated via induction of cell cycle arrest and apoptotic cell death. Cell Mol Life Sci 2005;62:881-93.

26. Tan W, Lu J, Huang M, et al. Anti-cancer natural products isolated from Chinese medicinal herbs. Chin Med 2011;6:27.

27. Tang X. Status and progress of basic researches of elemene injection for anti-tumor. China Cancer 2010;15:266-73.

28. Wu D, Li X, Zhao J, et al. A study of radiosensitivity of $\beta$-elemene to squamous cell carcinoma of tongue Tca-8113 cell line in vitro. Journal of Basic \& Clinical Oncology 2006.

29. Li LJ, Zhong LF, Jiang LP, et al. $\beta$-Elemene radiosensitizes lung cancer A549 cells by enhancing DNA damage and inhibiting DNA repair. Phytother Res 2011;25:1095-7.

30. Li QQ, Wang G, Zhang $M$, et al. beta-elemene, a novel plant-derived antineoplastic agent, increases cisplatin chemosensitivity of lung tumor cells by triggering apoptosis. Oncol Rep 2009;22:161-70.

31. Zhan YH, Liu J, Qu XJ, et al. $\beta$-elemene induces apoptosis in human renal-cell carcinoma 786-0 cells through inhibition of MAPK/ERK and PI3K/Akt/mTOR signalling pathways. Asian Pac J Cancer Prev 2012;13:2739-44.

32. Liu JS, Che XM, Chang S, et al. $\beta$-elemene enhances the radiosensitivity of gastric cancer cells by inhibiting Pak1 activation. World J Gastroenterol 2015;21:9945-56.

33. Dent P, Yacoub A, Fisher PB, et al. MAPK pathways in radiation responses. Oncogene 2003;22:5885-96.

34. He H, Baldwin GS. p21-activated kinases and gastrointestinal cancer. Biochimica Et Biophysica Acta 2013;1833:33-9.

35. Dummler B, Ohshiro KR, Field J. Pak protein kinases and their role in cancer. Cancer Metastasis Rev 2009;28:51-63.

36. Wang Z, Fu M, Wang L, et al. p21-Activated Kinase 1 (PAK1) Can Promote ERK Activation in a Kinaseindependent Manner. J Biol Chem 2013;288:20093-9.

37. Higgins JE. Cochrane Handbook for Systematic Reviews of Interventions. Naunyn-Schmiedebergs Archiv für experimentelle Pathologie und Pharmakologie 2011;5:S38.

38. Higgins JP, Green S. Cochrane Handbook for Systematic Reviews of Interventions Version 5.1.0. NaunynSchmiedebergs Archiv für experimentelle Pathologie und Pharmakologie 2011;5:S38.

39. Shen N, Niu D. Elemene Emulsion Combined with Linear Accelerator for the Treatment of Advanced Esophageal Carcinoma. Clinical Medicine of China 2000;16:555-6.

40. Cheng H, Yang Z. Clinical observation of elemene combined with in the treatment of advanced esophageal paclitaxel/tegafur carcinoma. Anhui Medical and Pharmaceutical 2012;16:1679-81.

41. Zhong H, Xiong S. Simultaneous chemotherapy plus elemene injection for esophageal carcinoma in 30 cases. Chinese Journal of Ethnomedicine and Ethnopharmacy 2012;21:89-90.

42. Liu X, Xia X. Comparison study of elemene injection, TP regimen combined with radiotherapy in the treatment of esophageal cancer. Chin Clin Oncol 2013;18:348-52.

43. Gu B, Hu J. Effect of the combination of Elemene and concurrent chemoradiation with cisplatin followed by consolidation chemotherapy with cisplatin and fluorouracil for locally advanced esophageal cancer. Chinese Journal of Clinical Oncology 2013;(10):600-3.

44. Ding $\mathrm{H}$, Liu $\mathrm{X}$. The radiosensitizing effect of elemene injection in the treatment of advanced esophageal cancer. Journal Nantong University 2013;33:182-4.

45. Song $Z$. Treatment of advanced esophageal carcinoma with elemene and whole body gamma knife. Shang Dong Medical Journal 2013;53:62-3.

46. Huang H, Gui W. Observation on the efficacy of elemene oral milk combined with three dimensional conformal radiotherapy for elderly patients with esophageal cancer. Journal of Clinical Medicine in Practice 2015;19:80-1.

47. Ji X, Wang B. Efficacy of elemene oral emulsion combined with TP chemotherapy protocol on the treatment of esophageal cancer. Beijing Medical Journal 2015;(4):363-5.

48. Chen Y, Zhou D. Clinical efficacy of orally elemene combined with TF chemotherapy for advanced esophageal cancer. Chinese Journal of Clinical Rational Brug Use 
2016;9:70-1.

49. Zhu X, Li J. Clinical observation of elemene for esophageal carcinoma in three-dimensional conformal radiotherapy. Chinese Pharmacy 2016;(14):1963-6.

50. Bai Y. Effect analysis of Elemene oral Fluorouracil in treatment emulsion combined with Cisplatin and of advanced esophageal cancer. Medical Journal of Chinese People's Health 2017;(24):75-6.

51. Chen J, Jin J. Elemene combined with three-dimensional conformal radiotherapy for treatment of advanced esophageal. Journal of Clinical Medicine in Practice 2018;(5):71.

52. Huang W, Qian M. Clinical Study Progress in Tumor Radiotherapy Combined with Traditional Chinese Medicines with Synergistic and Attenuated Effects. Chinese Pharmacist 2017;20:1374-81.

53. Jiang $X$, Hidru TH, Zhang Z, et al. Evidence of $\beta$-elemene injection combined radiotherapy in lung cancer treatment among patients with brain metastases: A systematic review and meta-analysis. Medicine (Baltimore) 2017;96:e6963.

54. Craig J, Fuchs T, Jenks M, et al. Systematic review and meta-analysis of the additional benefit of local prophylactic antibiotic therapy for infection rates in open tibia fractures treated with intramedullary nailing. Int Orthop 2014;38:1025-30.

55. Hu Z, Wu H, Li Y, et al. $\beta$-elemene inhibits the proliferation of esophageal squamous cell carcinoma by regulating long noncoding RNA-mediated inhibition of hTERT expression. Anticancer Drugs 2015;26:531-9.

56. Ren L, Xu L. Effect of $\beta$-elemene on Proliferation, Apoptosis and Activity of Caspase- 3 of the Human Esophageal Car. The Practical Journal of Cancer 2016;(2):202-4.

57. Choi YJ, Kang JS, Park JH, et al. Polyphenolic flavonoids differ in their antiapoptotic efficacy in hydrogen peroxide-treated human vascular endothelial cells. J Nutr 2003;133:985-91.

58. Xu HB, Zheng LP, Li L, et al. $\beta$-elemene, one ingredient of a Chinese herb, against malignant tumors: a literaturebased meta-analysis. Cancer Invest 2013;31:156-66.

59. Yang Y, Zhang H. Research Progress of Resveratrol in Enhancing Mechanism of Radiotherapy for Tumor. Chinese Journal of Laboratory Diagnosis 2014;(5):861-3.

60. Pirayesh Islamian J, Mohammadi M, Baradaran B, et al. Enhancing radiosensitivity of TE1, TE8, and TE 11 esophageal squamous carcinoma cell lines by Hdm2-siRNA targeted gene therapy in vitro. Bioimpacts 2016;6:93-8.

61. Tan B. The Clinical Prognosis Significance and Radiosensitivity Prediction Value of PAX9 in Esophageal Squamous Cell Carcinoma. Shan Dong University, 2016.
62. Smyth MJ, Godfrey DI, Trapani JA. A fresh look at tumor immunosurveillance and immunotherapy. Nat Immunol 2001;2:293-9.

63. Wells AD, Malkovsky M. Heat shock proteins, tumor immunogenicity and antigen presentation: an integrated view. Immunol Today 2000;21:129-32.

64. Guo L, Shi G, Gao Z, et al. Response to hepatocarcinoma Hca-F of mice immunized with heat shock protein 70 from $\beta$-elemene combo tumor cell vaccine. Cell Mol Immunol 2006;3:291-5.

65. Huang C, Yu Y. Synergistic Cytotoxicity of $\beta$-Elemene and Cisplatin in Gingival Squamous Cell Carcinoma by Inhibition of STAT3 Signaling Pathway. Med Sci Monit 2017;23:1507-13.

66. Li QQ, Wang G, Reed E, et al. Evaluation of cisplatin in combination with $\beta$-elemene as a regimen for prostate cancer chemotherapy. Basic Clin Pharmacol Toxicol 2010;107:868-76.

67. Reed E. DNA damage and repair in translational oncology: an overview. Clin Cancer Res 2010;16:4511-6.

68. Ferry KV, Hamilton TC, Johnson SW. Increased nucleotide excision repair in cisplatin-resistant ovarian cancer cells: role of ERCC1-XPF. Biochem Pharmacol 2000;60:1305-13.

69. Li QQ, Lee RX, Liang H, et al. $\beta$-elemene enhances susceptibility to cisplatin in resistant ovarian carcinoma cells via downregulation of ERCC-1 and XIAP and inactivation of JNK. Int J Oncol 2013;43:721-8.

70. Eich M, Roos WP, Nikolova T, et al. Contribution of ATM and ATR to the Resistance of Glioblastoma and Malignant Melanoma Cells to the Methylating Anticancer Drug Temozolomide. Mol Cancer Ther 2013;12:2529-40.

71. Begg AC, Stewart FA, Vens C. Strategies to improve radiotherapy with targeted drugs. Nat Rev Cancer 2011;11:239-53.

72. Liu S, Zhou L, Zhao Y, et al. $\beta$-elemene enhances both radiosensitivity and chemosensitivity of glioblastoma cells through the inhibition of the ATM signaling pathway. Oncol Rep 2015;34:943-51.

73. Lingani M, Akita T, Ouoba S, et al. High prevalence of hepatitis B infections in Burkina Faso (1996-2017): a systematic review with meta-analysis of epidemiological studies. BMC Public Health 2018;18:551.

Cite this article as: Li C, Zeng Y, Zhang N, Zhai B, Zhang C, Zhu Y, Zeng Z, Xie T. The clinical effect of $\beta$-elemeneassisted radiochemotherapy in the treatment of esophageal cancer: a systematic review and meta-analysis. Transl Cancer Res 2018;7(6):1586-1600. doi: 10.21037/tcr.2018.12.05 